\title{
Simultaneous Determination of Pyrazinamide, Rifampicin, Ethambutol, Isoniazid and Acetyl Isoniazid in Human Plasma by LC-MS/MS Method
}

\author{
Le Thi Luyen ${ }^{1}$, Ta Manh Hung ${ }^{2}$, Le Thu Huyen ${ }^{2}$, Le Anh Tuan, Duong Thi Ly Huong ${ }^{1}$, Hoang Van Duc ${ }^{2}$, Bui Thanh Tung ${ }^{1 *}$ \\ ${ }^{1}$ School of Medicine and Pharmacy, Vietnam National University Hanoi, Vietnam. \\ ${ }^{2}$ Center for Bioequivalence Assessment, National Institute of Drug Quality Control, Vietnam National University, Ha Noi, Vietnam.
}

\begin{tabular}{|c|c|}
\hline ARTICLE INFO & ABSTRACT \\
\hline $\begin{array}{l}\text { Article history: } \\
\text { Received on: } 28 / 04 / 2018 \\
\text { Accepted on: } 07 / 07 / 2018 \\
\text { Available online: } 30 / 09 / 2018\end{array}$ & $\begin{array}{l}\text { Monitoring of anti-tuberculosis drug concentrations in human plasma is very important in the treatment of TB } \\
\text { disease. In this study, we described a method that can rapidly and simultaneously measure the plasma concentrations } \\
\text { of four anti-tuberculosis drugs (isoniazid, rifampicin, pyrazinamide, and ethambutol) and one major metabolite } \\
\text { (acetylisoniazid) using high-performance liquid chromatography/tandem mass spectrometry (HPLC/MS/MS). } \\
\text { To adjust for degradation and losses during sample preparation. Diltiazem hydrochloride was used as an internal }\end{array}$ \\
\hline $\begin{array}{l}\text { Key words: } \\
\text { Pyrazinamide; Rifampicin; } \\
\text { Isoniazid; Acetyl Isoniazid; } \\
\text { Ethambutol; LC-MS/MS; } \\
\text { Tuberculosis. }\end{array}$ & $\begin{array}{l}\text { standard. Samples were prepared by using protein precipitation with methanol. Four drugs and one metabolite were } \\
\text { simultaneously separated by using the high-performance liquid chromatography system with Gemini C18 column } \\
\text { and a mobile phase consisting of } \mathrm{MeOH} \text { and Ammonium acetate } 5 \mathrm{mM}, \mathrm{pH} 3.5 \text {. The method was found to have } \\
\text { high selectivity. Precision estimated by the coefficient of variation was }<15 \% \text { for all drugs. The linear range of the } \\
\text { calibration curve for PZA } 1.0-100 \mu \mathrm{g} / \mathrm{mL} \text {; RIF } 0.2-20 \mu \mathrm{g} / \mathrm{mL} \text {; INH } 0.1-10 \mu \mathrm{gL} ; \mathrm{mcINH} 0.1-10 \mu \mathrm{g} / \mathrm{mL} \text {; and EMB } \\
20-5000 \mathrm{ng} / \mathrm{mL} \text {. The lower limit of quantification was } 1 \mu \mathrm{g} / \mathrm{mL} ; 0.2 \mu \mathrm{g} / \mathrm{mL} ; 0.1 \mu \mathrm{g} / \mathrm{mL} ; 0.1 \mu \mathrm{g} / \mathrm{mL} \text { and } 20 \mathrm{ng} / \mathrm{mL} \text {, } \\
\text { respectively. The results of validation for specificity/selectivity, precision, accuracy, linearity, limit of quantification, } \\
\text { recovery, and stability show that the method meets the requirements of a bioanalytical method. Our method may serve } \\
\text { well for routine therapeutic monitoring of the first-line anti-TB drugs in patient plasma. }\end{array}$ \\
\hline
\end{tabular}

\section{INTRODUCTION}

Tuberculosis (TB) is a major public health issue in Vietnam. Vietnam is ranked $12^{\text {th }}$ among the 22 highest TB burden countries with an estimated incidence of 140 new cases per 100,000 in 2014 (Hoa et al., 2010). National TB Control Programme (NTP) data indicates that 6 months of first-line month therapy for new TB patients results in $10 \%$ treatment failures or post-treatment relapses. TB treatment is very long and complex, unfortunately, many patients fail treatment even though they have fully susceptible TB infections that should, in theory, respond to the treatment (Mukherjee et al., 2004). The treatment of TB consists of combinatorial regimens of three

${ }^{*}$ Corresponding Author

Dr. Bui Thanh Tung, School of Medicine and Pharmacy, Vietnam National University, Ha Noi 144 Xuan Thuy, Cau Giay, Ha Noi, Vietnam.E-mail: tungasia82@yahoo.es or four first-line drugs to prevent resistance such as isoniazid, rifampicin, pyrazinamide, and ethambutol. Even there are the majority of tuberculosis patients who respond to a standardized short course of treatment, but it has been reported that a small group of patients has a poor response to treatment (Mirsaeidi et al., 2018). These patients have low serum drug concentrations, leading to clinical failure or relapse. For patients who failure to standard therapy and presented low drug concentrations, the treatment could be successfully improved by adjusting dose regimens (Alsultan et al., 2014). Therefore, it is necessary to have an efficient method to measure the standard antituberculosis drug concentrations to facilitate early screening of therapeutic failure. Several studies reported the analytical method for measurement of anti-tuberculosis drug concentrations in human plasma, but there are a few methods that could simultaneously measure first-line drugs and their major metabolites. Mukherjee et al., have studied four drugs, including isoniazid, rifampicin, 
pyrazinamide, and ethambutol in children to correlate the plasma concentrations of these drugs with clinical outcome of therapy (Mukherjee et al., 2015). The LC-MS/MS method may be the most appropriate one for measurement of anti-TB drug concentration in human plasma which has been reported (Song et al., 2007, Um et al., 2007). However, previous LC-MS/MS methods developed could only measure a limited number of anti-TB drugs, then leading time-consuming to determine all four drugs. In the present study, we developed a simple and rapid method for the simultaneous measurement of plasma concentrations of four first-line drugs (pyrazinamide, rifampicin, isoniazid, ethambutol) and acetylisoniazid, one major metabolite using LC/MS/MS to apply for therapeutic drug monitoring.

\section{MATERIALS AND METHODS}

\section{Chemicals and reagents}

Standard of Pyrazinamide, Rifampicin, Isoniazid, Ethambutol hydrochloride and Diltiazem hydrochloride from NIDQC; Acetyl Isoniazid from Canada; Methanol, Ammonium acetate (Merck, Germany); All blank plasma sources were collected from healthy volunteers.

\section{Sample preparation}

- Stock solutions of PZA $(2000 \mu \mathrm{g} / \mathrm{mL}), \mathrm{RIF}(400 \mu \mathrm{g} /$ $\mathrm{mL}), \mathrm{INH}(400 \mu \mathrm{g} / \mathrm{mL})$, AcINH $(500 \mu \mathrm{g} / \mathrm{mL})$ and EMB $(200 \mu \mathrm{g} /$ $\mathrm{mL}$ ) in methanol were made.

- Working standard solutions of $200 \mu \mathrm{g} / \mathrm{mL}$ PZA, $40 \mu \mathrm{g} /$ $\mathrm{mL}$ RIF, $20 \mu \mathrm{g} / \mathrm{mL}$ INH, $20 \mu \mathrm{g} / \mathrm{mL}$ AcINH and $10 \mu \mathrm{g} / \mathrm{mL}$ EMB in plasma were prepared from the stock solutions.

- A calibration curve consists of a blank sample, a zero sample and eight non-zero plasma standards spiked with PZA, RIF, INH, AcINH, EMB and IS.

- Three quality control (QC) concentration levels: LQC (Low-quality control), MQC (Medium-quality control), HQC (High-quality control) and LLOQ (Lower limit of quantification) were constructed from separate stock standard solutions (Table 1). Sample preparation and sample treatment procedure were protected from light.

Table 1: QC samples in plasma.

\begin{tabular}{cccccc}
\hline \multirow{5}{*}{ Sample } & \multicolumn{5}{c}{ Concentration } \\
\cline { 2 - 6 } & $\begin{array}{c}\text { PZA } \\
(\mu \mathrm{g} / \mathbf{m L})\end{array}$ & $\begin{array}{c}\text { RIF } \\
(\mu \mathrm{g} / \mathbf{m L})\end{array}$ & $\begin{array}{c}\text { INH } \\
(\mu \mathrm{g} / \mathbf{m L})\end{array}$ & $\begin{array}{c}\text { AcINH } \\
(\boldsymbol{\mu g} / \mathbf{m L})\end{array}$ & $\begin{array}{c}\text { EMB } \\
(\mathbf{n g} / \mathbf{m L})\end{array}$ \\
\hline LQC & 3 & 0.6 & 0.3 & 0.3 & 60 \\
MQC & 50 & 10 & 5 & 5 & 2500 \\
HQC & 80 & 16 & 8 & 8 & 4000 \\
LLOQ & 1.0 & 0.2 & 0.1 & 0.1 & 20 \\
\hline
\end{tabular}

Internal standard (IS) stock solution (Diltiazem hydrochloride) was prepared at $250 \mu \mathrm{g} / \mathrm{mL}$ in methanol. IS working solution was prepared by diluting the IS stock solution in methanol: water $(1: 1, \mathrm{v} / \mathrm{v})$ to get the concentration of $50 \mu \mathrm{g} / \mathrm{mL}$.

\section{Sample preparation}

To $0.5 \mathrm{~mL}$ of plasma sample, add $50 \mu \mathrm{L}$ of IS (Diltiazem hydrochloride) working solution, vortex for 5 seconds. And then $1.5 \mathrm{~mL}$ of $\mathrm{MeOH}$ was added and followed by vortexing for 10 seconds. $250 \mu \mathrm{L}$ of water was also added and mixed well for 5 seconds. Centrifuge at $9000 \mathrm{rpm} / \mathrm{min}$ for 5 minutes. Pipette the clear supernatant and inject into the LC-MS/MS system.

\section{Analytical method validation}

The analysis was performed on a triple quadrupole LC-MS/MS (Waters-USA) with a Surveyor MS pump (Acquity H class QSM) and autosampler (Acquity H class FTN). The mass spectrometer was a TSQ Quantum Access Max mass spectrometer. The autosampler tray temperature was set at $10^{\circ} \mathrm{C}$. The highperformance liquid chromatography (HPLC) system was coupled to a quadrupole mass spectrometer. The HPLC components were chromatographic column: Gemini C18; $150 * 4.6 \mathrm{~mm} ; 4.6 \mu \mathrm{m}$; Guard Column: C18; $4 \times 3 \mathrm{~mm}$; Column temperature $40^{\circ} \mathrm{C}$; Detector: Xevo TQD. The mobile phase containing $\mathrm{MeOH}$ : and Ammonium acetate $5 \mathrm{mM}, \mathrm{pH} 3.5$. The elution gradient was shown in Table 2. Injection volume: $1 \mu \mathrm{L}$; The method had a run time of $8 \mathrm{~min}$. The mass spectrometric conditions were shown in Table 3.

Table 2: Gradient program of the mobile phase.

\begin{tabular}{cccc}
\hline Time (min) & $\begin{array}{c}\text { Flow rate } \\
(\boldsymbol{\mu} \mathbf{L} / \mathbf{m i n})\end{array}$ & $\begin{array}{c}\text { MeOH } \\
(\%)\end{array}$ & $\begin{array}{c}\text { Ammonium acetate 5 mM } \\
\mathbf{p H} \mathbf{3 . 5}(\mathbf{\%})\end{array}$ \\
\hline 0.0 & 600 & 60 & 40 \\
2.0 & 600 & 60 & 40 \\
2.5 & 700 & 90 & 10 \\
5.0 & 700 & 90 & 10 \\
6.0 & 600 & 60 & 40 \\
8.0 & 600 & 60 & 40 \\
\hline
\end{tabular}

The validation was performed based on the US Food and Drug Administration (FDA) guidelines (Health et al., 2017) and European Medicines Agency (EMA) guidelines (Agency, 2011) and parameters included were selectivity and specificity, linearity, accuracy and precision, matrix effects, recovery, carry over, dilution integrity and stability in human plasma.

\section{System suitability test (SST)}

We analyzed MQC sample in plasma following the analytical procedure for system suitability test. Injected this sample with six replicates. All chromatograms and peak parameters were recorded.

\section{Selectivity}

Selectivity was assessed by comparing chromatograms and peak responses of 06 blank plasma samples collected from 6 different volunteers with 06 standard samples spiked with IS and PZA, RIF, INH, AcINH, EMB at LLOQ level $(1.0 \mu \mathrm{g} / \mathrm{mL} ; 0.2$ $\mu \mathrm{g} / \mathrm{mL} ; 0.1 \mu \mathrm{g} / \mathrm{mL} ; 0.1 \mu \mathrm{g} / \mathrm{mL}$ and $20 \mathrm{ng} / \mathrm{mL}$, respectively) in 6 above blank plasma sources, respectively. 
Table 3: Mass spectrometric conditions.

\begin{tabular}{|c|c|c|c|c|c|c|}
\hline $\begin{array}{c}\text { Analytes } \\
\text { Parameters } \\
\end{array}$ & Pyrazinamide & Rifampicin & Isoniazid & Acetyl Isoniazid & Ethambutol & Diltiazem (IS) \\
\hline Ion source & ESI $(+)$ & ESI $(+)$ & ESI (+) & ESI $(+)$ & ESI $(+)$ & ESI $(+)$ \\
\hline Capillary voltage (kV) & 3.5 & 3.5 & 3.5 & 3.5 & 3.5 & 3.5 \\
\hline Desolvation temperature $\left({ }^{\circ} \mathrm{C}\right)$ & 500 & 500 & 500 & 500 & 500 & 500 \\
\hline Desolvation gas $(\mathrm{L} / \mathrm{H})$ & 800 & 800 & 800 & 800 & 800 & 800 \\
\hline Precusor ion (Dalton) & 124.00 & 823.46 & 138.00 & 180.00 & 205.16 & 415.10 \\
\hline Product ion (Dalton) & 81.00 & 791.49 & 121.00 & 121.00 & 116.13 & 178.00 \\
\hline
\end{tabular}

\section{Matrix effects}

The matrix effects were assessed at LQC and HQC levels by comparing chromatograms and peak area of following samples: 06 blank plasma samples collected from six different volunteers; standard samples containing IS and PZA, RIF, INH, AcINH, EMB at LQC and HQC concentration in each above matrix; six standard samples containing IS and PZA, RIF, INH, AcINH, EMB at LQC and HQC concentration in the solvent mixture (methanol and water). Determine the matrix factor: $\mathrm{MF}_{\mathrm{PZA}}, \mathrm{MF}_{\mathrm{RIF}}, \mathrm{MF}_{\mathrm{INH}}, \mathrm{MF}_{\mathrm{AcINH}}$, $\mathrm{MF}_{\mathrm{EMB}}, \mathrm{MF}_{\mathrm{IS}}$ and the ratio: $\mathrm{MF}_{\mathrm{PZA}} / \mathrm{MF}_{\mathrm{IS}}, \mathrm{MF}_{\mathrm{RIF}} / \mathrm{MF}_{\mathrm{IS}}, \mathrm{MF}_{\mathrm{INH}} / \mathrm{MF}_{\mathrm{IS}}$, $\mathrm{MF}_{\text {AcINH }} / \mathrm{MIS}$ and $\mathrm{MF}_{\mathrm{EMB}} / \mathrm{MF}_{\mathrm{IS}}$.

Carry-over

The carry-over was analyzed as follows:

Prepared samples:

- Six blank human plasma samples;

- Six standard samples in human plasma at LLOQ concentration; six standard samples in human plasma at ULOQ (Upper limit of quantification) concentration. Then these samples were extracted following the procedure. Injected 06 LLOQ samples firstly and then injected a blank sample after each ULOQ sample, alternately. Record all the chromatograms and peak area.

\section{Calibration curve and linearity range}

Evaluated the concentration range of PZA: $1.0 \mu \mathrm{g} /$ $\mathrm{mL}-100 \mu \mathrm{g} / \mathrm{mL}$; RIF: $0.2 \mu \mathrm{g} / \mathrm{mL}-20 \mu \mathrm{g} / \mathrm{mL}$; INH: $0.1 \mu \mathrm{g} /$ mL-10 $\mu \mathrm{g} / \mathrm{mL}$; AcINH: $0.1 \mu \mathrm{g} / \mathrm{mL}-10 \mu \mathrm{g} / \mathrm{mL}$ and EMB: $20 \mathrm{ng} /$ $\mathrm{mL}-5000 \mathrm{ng} / \mathrm{mL}$. Each calibration curve includes 8 standard samples. Analyze these samples following the procedure. Record all the chromatograms and peak area. From the experimental data, choose the most appropriate weighting factor from the popular weighting models: $1,1 / \mathrm{x}, 1 / \mathrm{x}^{2}, 1 / \mathrm{x}^{1 / 2}$. Determine the accuracy of each standard sample.

\section{Determination of lower limit of quantification}

The lower limit of quantification (LLOQ) is the lowest concentration on the calibration curve to demonstrate that the developed analytical method is specific/selective, precise and accurate. LLOQ was assessed by preparing six blank human plasma samples; six blank plasma spiked with PZA, RIF, INH, AcINH and EMB at concentration of about: $1.002 \mu \mathrm{g} / \mathrm{mL} ; 0.199$ $\mu \mathrm{g} / \mathrm{mL} ; 0.105 \mu \mathrm{g} / \mathrm{mL} ; 0.106 \mu \mathrm{g} / \mathrm{mL} ; 20.0 \mathrm{ng} / \mathrm{mL}$; respectively and IS; one calibration curve with eight standard samples in human plasma. Recorded all the chromatograms and peak responses and determined the accuracy and precision of the LLOQ samples.

\section{Intra-day and inter-day accuracy and precision}

Intra-day precision and accuracy were evaluated at 4 concentrations: LLOQ, LQC, MQC, and HQC. Each concentration was repeated six replicates. Inter-day accuracy and precision have evaluated the accuracy and precision of the analytical method on five different analytical days and determine inter-day precision at each QC level and LLOQ. Requirements for method is intra-day accuracy and precision was the Mean \pm SD accuracy at each QC level should be within $85 \%-115 \%$ of the nominal concentration, except for the LLOQ which should be $80 \%-120 \%$ of the nominal concentration; and intra-day precision at each QC level should not exceed $15 \%$ of the CV\% value, except for the LLOQ where it should not exceed $20 \%$ of the CV\% value.

\section{Recovery}

The extraction recovery was evaluated by determining the recovery of the analytical method at 3 concentration levels: LQC, MQC, and HQC in six replicates. The recovery of the drugs should not exceed $100 \%$, but the extent of recovery of the drugs and the internal standard should be consistent with each other (Zhou et al., 2013).

\section{Dilution integrity}

When the concentrations of the drugs are higher than the upper limit of quantification (ULOQ) of the calibration curves, the sample should be diluted. Dilution integrity experiments were performed with three LDC, MDC and HDC samples. Dilute these samples 2 times by blank plasma. Prepare a calibration curve and QC samples in plasma. Analyze the above samples following the analytical procedure and determine the concentrations, accuracy, and precision of diluted samples. Dilution integrity was achieved if the mean accuracy should be $85-115 \%$ of the nominal concentration and the precision should not exceed $15 \%$ of the $\mathrm{CV}$.

\section{Stability}

Autosampler stability of processed plasma samples was evaluated at LQC and HQC concentrations. These samples were extracted following the proposed procedure and stored in autosampler at $10^{\circ} \mathrm{C}$. One part of the processed sample volume was injected immediately to determine the initial concentration. The remaining sample volume was still stored in autosampler 
until it was analyzed to determine the concentration after 20 hours.

Short-term stability of plasma samples was evaluated at LQC and HQC concentrations. The QC samples were stored at room temperature for 2, 4 hours. Determined the concentration of those samples. The stability samples were analyzed against with the calibration curve.

Long-term stability of plasma samples was also evaluated at LQC and HQC concentrations which were stored at $-70^{\circ} \mathrm{C} \pm 5^{\circ} \mathrm{C}$. Determined the concentration of those samples after 5 days and 18 days.

\section{RESULTS AND DISCUSSION}

Choosing a positive or negative ion mode in the LC-MS/ MS method depends on the molecular structure of the analytes.
In the molecular structure of all compounds PZA, RIF, EMB, $\mathrm{INH}$, and AcINH, there is an amino group-a functional group containing $\mathrm{N}$ atom and an unused free pair of electrons capable of accepting $\mathrm{H}^{+}$to become positively charged ion, therefore PZA, RIF, INH, ACINH, and EMB were better detected in the positive ion mode. Furthermore, previous studies also used all positive ion mode (Prahl et al., 2016). The product ion spectrum of the $\left[\mathrm{M}^{+} \mathrm{H}\right]^{+}$ ion of PZA showed a major fragment ion at $m / z$ 81, of RIF, major fragment ions were observed at $\mathrm{m} / z 792$ due to the loss of neutral $\mathrm{CH}_{3} \mathrm{OH}$, of INH showed a major fragment ion at $\mathrm{m} / \mathrm{z} 121$ due to loss of neutral $\mathrm{NH}_{3}$, and AcIHN showed the same fragment ion at $m / z 121$, and for EMB the major fragment ions were at $m / z$ 116 , and diltiazem hydrochloride had fragment ion at $\mathrm{m} / z 178$ as showed in Figure 1 (Molden et al., 2003, Song et al., 2007).

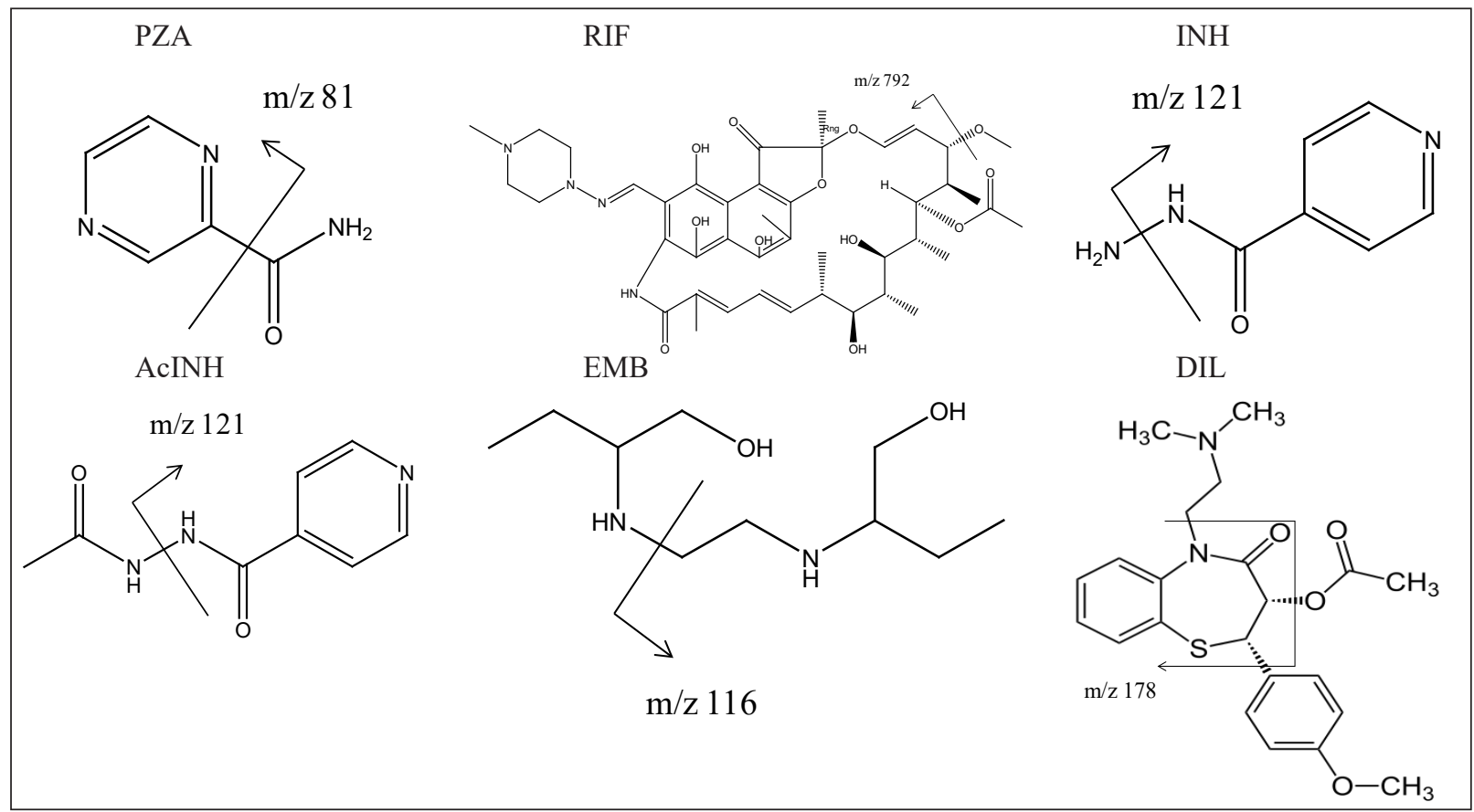

Fig. 1: Chemical structures and product ions of the four tuberculosis drugs (isoniazid, rifampicin, pyrazinamide, and ethambutol) examined, one metabolite (acetylisoniazid), and internal standards (Diltiazem hydrochloride).

\section{System suitability test}

Our results showed the method had a system suitability test because:

- The peak of analytes (PZA, RIF, INH, AcINH, and EMB) and IS was symmetrical and identifiable;

- Repeatability of the retention time of analytes and IS was not exceeded $1.0 \%$ of the $\mathrm{CV} \%$ value.

- Repeatability of analytes, IS peak area and each analyte/IS peak area ratio did not exceed $5.0 \%$ of the CV\% value.

The results were presented in Figure 2.

\section{Selectivity}

The method was found to have high selectivity because Peak of PZA, RIF, INH, AcINH, EMB and IS was symmetrical and identifiable; At the retention time of PZA, RIF, INH, AcINH, and $\mathrm{EMB}$, peak response of each LLOQ sample was at least 5 times the response of respective blank plasma sample; At the retention time of IS, peak response of each LLOQ sample was at least 20 times the response of respective blank plasma sample. Chromatogram blank plasma sample and blank plasma sample spiked with IS and PZA, RIF, INH, AcINH, EMB standard at LLOQ concentration are presented in Figure 3 and Figure 4. The analyzed method is based on the LC-MS/MS technique, which is a highly selective and specific analytical method. The quantitative principle of the method is based on the recognition of the mass number of both the product ion and precursor ion. Therefore, if the two analytes have different mass number of product ion and precursor ion, they will be independently identified and quantified without being confused. In the method, the precursor/product ion of metabolites should have a different mass number of precursor/ product ion of analytes. In this study, for PZA: 124/81 Dalton; metabolite: Pyrazinoic acid: $125.0 \rightarrow 80.9$ Dalton; 5 hydroxy pyrazinoic: $141.0 \rightarrow 81.0$ Dalton; for RIF: $823.46 / 791.49$ Dalton; metabolite: 25-0-desacetylrifampin: 781.1-749.1 Dalton; for 
INH: 138.00/121.00 Dalton; metabolite: AcINH: 180.00/121.00 Dalton; and for EMB: 205.16/116.13 Dalton.

\section{Matrix effect}

The use of internal standards compensates for unexpected matrix effects. The calculated $\mathrm{CV} \%(n=6)$ of the internal standard normalized matrix factor is presented in Table 4 . The calculated $\mathrm{CV} \%$ of the internal standard normalized matrix factor was not exceeding $15 \%$ of the $\mathrm{CV} \%$ value.

\section{Carry-over}

No carry-over was observed for PZA, RIF, INH, AcINH, and EMB based on the retention time of PZA, RIF, INH, AcINH and $\mathrm{EMB}$, the Mean \pm SD peak area of LLOQ sample was at least 5 times the response of blank sample and at the retention time of
IS, the Mean \pm SD peak area of LLOQ sample was at least 20 times the response of blank sample.

\section{Calibration curve}

The accuracy of standards was within $85 \%-115 \%$ of nominal concentration for all eight calibration standards of PZA, RIF, INH, ACIH, and EMB, then the calibration curve of PZA, RIF, INH, ACIH, and EMB consisted of all eight calibration standards. From the experimental data, the weighting factor of $1 /$ $\mathrm{x} 2$ was chosen. Results of experimental calibration curves with the weighting factor of $1 / \mathrm{x} 2$ and calibration equations of the standard curves were presented in Figure 5. PZA, RIF, INH, AcINH and EMB showed an acceptable linear response in the range 1.0-100 $\mu \mathrm{g} / \mathrm{mL} ; 0.2-20 \mu \mathrm{g} / \mathrm{mL} ; 0.1-10 \mu \mathrm{g} / \mathrm{mL} ; 0.1-10 \mu \mathrm{g} / \mathrm{mL} ; 20-5000$ $\mathrm{ng} / \mathrm{mL}$, respectively.

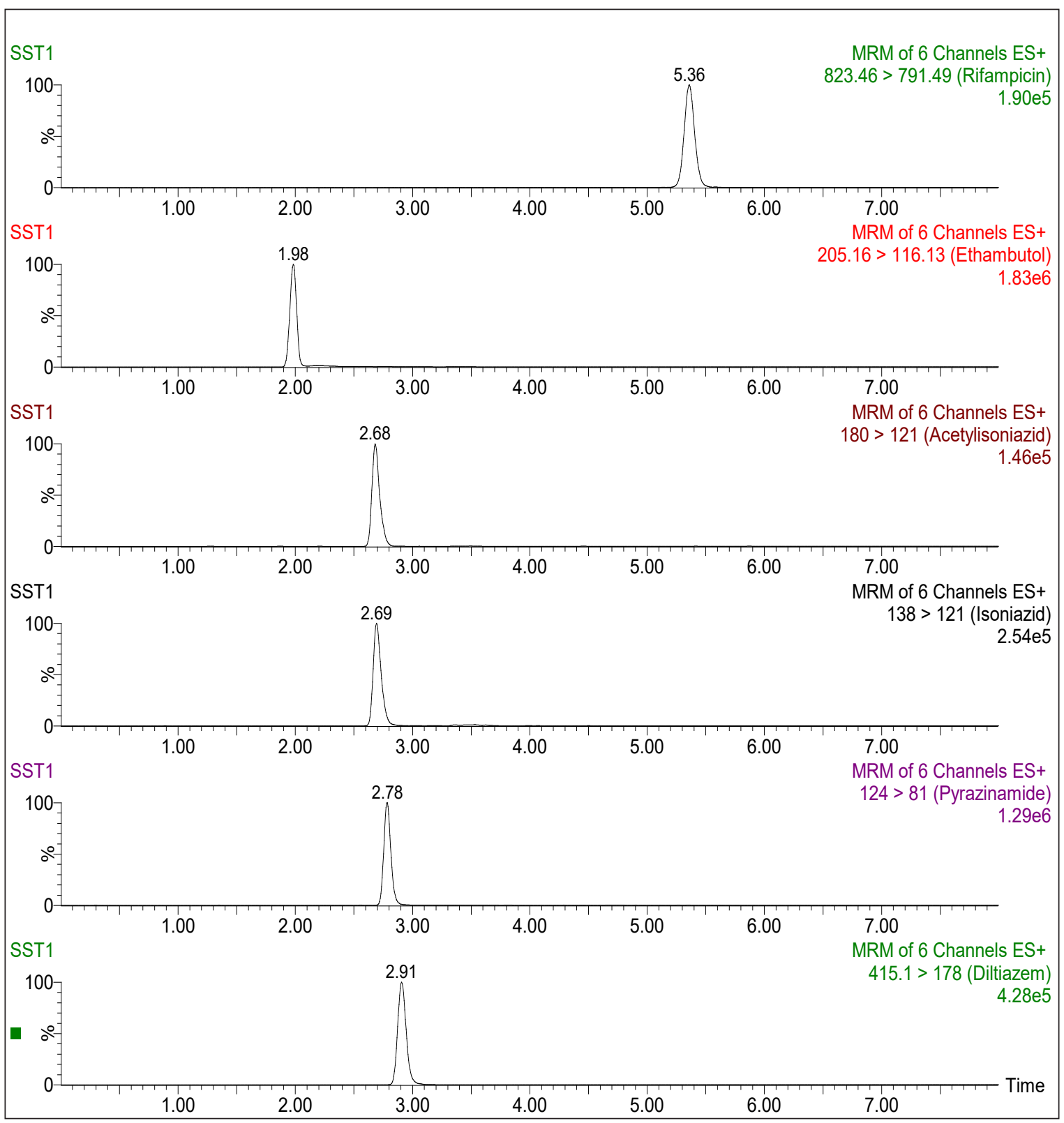

Fig. 2: Chromatogram of blank plasma spiked with IS and PZA, RIF, INH, AcINH and EMB standards at MQC concentration. 
Lower limit of quantification

Requirements for LLOQ sample was: at the retention time of PZA, RIF, INH, AcINH and EMB, response of the separate LLOQ sample should be at least 5 times the response of blank sample respective; and accuracy of the LLOQ sample should be $80 \%-120 \%$ of the nominal concentration; and precision should not exceed $20 \%$ of the CV\% value. Results were presented in Table 5. Our methods showed the LLOQ for all compounds was below the recommended normal ranges. LLOQ of PZA was 1.0 $\mu \mathrm{g} / \mathrm{mL}$; of RIF $0.2 \mu \mathrm{g} / \mathrm{mL}$; of INH $0.1 \mu \mathrm{g} / \mathrm{mL}$; of AcINH $0.1 \mu \mathrm{g} /$ $\mathrm{mL}$ and of EMB $20 \mathrm{ng} / \mathrm{mL}$.

Table 4: Results of matrix effect- PZA, RIF, INH, AcINH, and EMB.

\begin{tabular}{|c|c|c|c|c|c|c|c|c|c|c|}
\hline & \multicolumn{2}{|c|}{ PZA } & \multicolumn{2}{|c|}{ RIF } & \multicolumn{2}{|c|}{ INH } & \multicolumn{2}{|c|}{ AcINH } & \multicolumn{2}{|c|}{ EMB } \\
\hline & LQC & HQC & LQC & HQC & LQC & HQC & LQC & HQC & LQC & HQC \\
\hline & $\mathbf{M F}_{\mathrm{PZA}} / \mathbf{M F}_{\mathrm{IS}}$ & $\mathbf{M F}_{\mathrm{PZA}} / \mathbf{M F}_{\text {IS }}$ & $\mathbf{M F}_{\mathrm{RIF}} / \mathbf{M F}_{\mathrm{IS}}$ & $\mathbf{M F}_{\mathrm{RIF}} / \mathbf{M F}_{\mathrm{IS}}$ & $\mathrm{MF}_{\mathrm{INH}} / \mathrm{MF}_{\mathrm{IS}}$ & $\mathbf{M F}_{\mathrm{INH}} / \mathbf{M F}_{\mathrm{IS}}$ & $\mathrm{MF}_{\mathrm{AcINH}} / \mathrm{MF}_{\mathrm{IS}}$ & $\mathbf{M F}_{\mathrm{AcINH}} / \mathbf{M F}_{\text {IS }}$ & $\mathrm{MF}_{\mathrm{EMB}} / \mathbf{M F}_{\text {IS }}$ & $\mathrm{MF}_{\mathrm{EMB}} / \mathrm{MF}_{\mathrm{IS}}$ \\
\hline $\begin{array}{c}\text { Mean } \pm \\
\text { SD }\end{array}$ & $0.588 \pm 0.08$ & $0.590 \pm 0.06$ & $0.616 \pm 0.07$ & $0.647 \pm 0.07$ & $1.117 \pm 0.12$ & $1.128 \pm 0.16$ & $1.185 \pm 0.18$ & $1.123 \pm 0.13$ & $0.433 \pm 0.06$ & $0.409 \pm 0.04$ \\
\hline CV (\%) & 12.9 & 10.4 & 11.5 & 11.1 & 10.7 & 13.9 & 15.0 & 11.3 & 13.9 & 10.4 \\
\hline
\end{tabular}

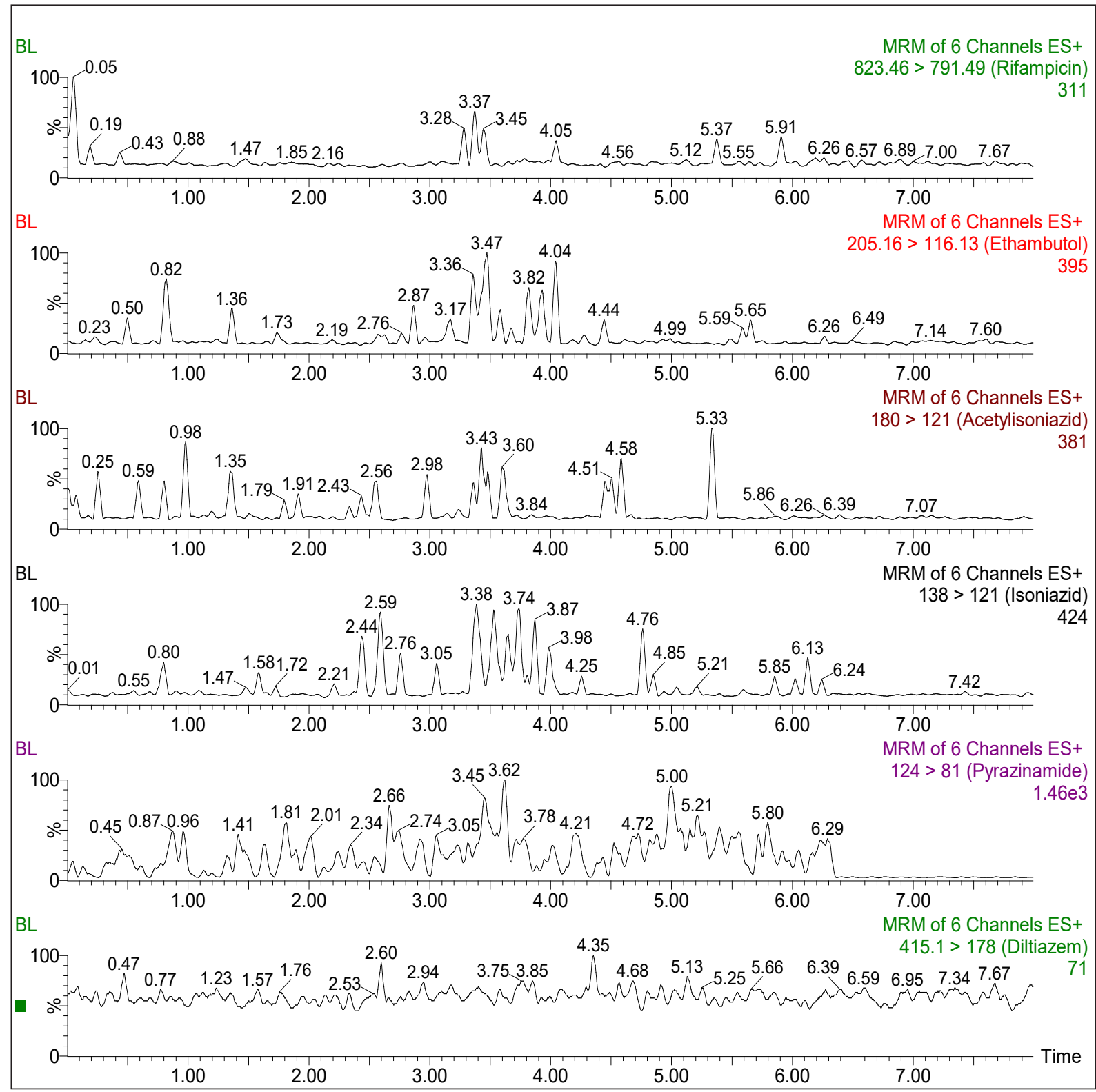

Fig. 3: Chromatogram of blank plasma sample. 


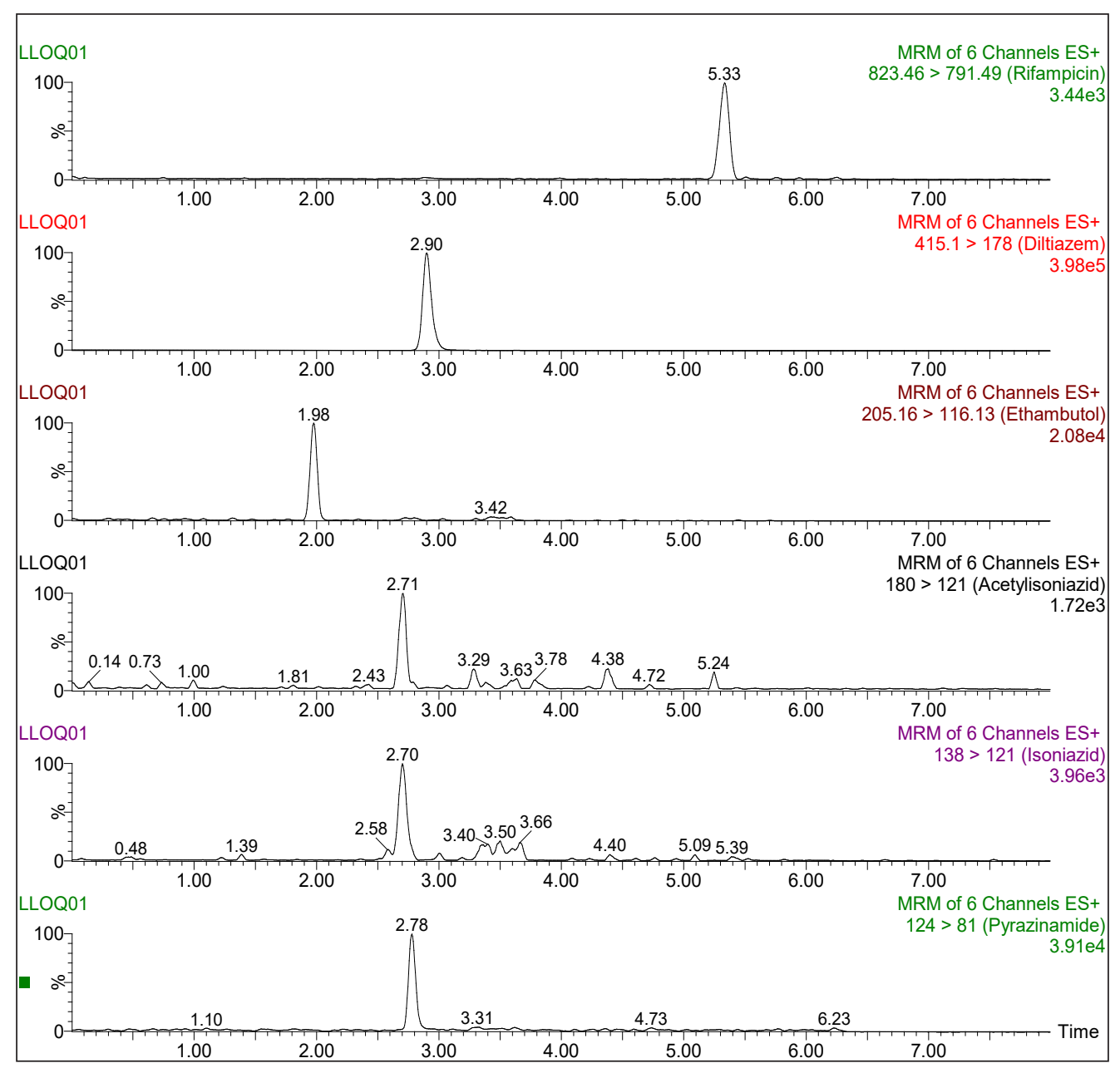

Fig. 4: Chromatogram of blank plasma sample spiked with IS and PZA, RIF, INH, AcINH, and EMB standard at LLOQ concentration.

Table 5: Accuracy and precision at LLOQ level: PZA, RIF, INH, AcINH, and EMB.

\begin{tabular}{cccccc}
\hline & PZA & RIF & INH & AcINH & EMB \\
\hline $\begin{array}{c}\text { Accu. } \\
(\%)\end{array}$ & $105.8 \pm 9.5$ & $102.0 \pm 6.3$ & $99.9 \pm 15.4$ & $\begin{array}{c}100.6 \pm \\
10.5\end{array}$ & $90.4 \pm 10.1$ \\
$\begin{array}{c}\text { CV } \\
(\%)\end{array}$ & 9.0 & 6.2 & 15.5 & 10.5 & 11.1 \\
\hline
\end{tabular}

\section{Intra-day accuracy and precision}

Our method was found to be acceptably precise and accurate as the intra-day precision were $<15 \%$ (Table 6 ). In this study, we used Diltiazem hydrochloride as internal standards. We found that the use of internal standards was necessary in order to obtain the desired accuracy and $\mathrm{CV} \%$. RIF and INH are labile compounds and the use of internal standards helps to compensate for the degradation during sample preparation.

\section{Inter-day precision}

The method was also found to be acceptably precise and accurate as inter-day precision were $<15 \%$ (Table 7 ) as the requirements for Inter-day precision was the inter-day precision at each QC level should not exceed $15 \%$ of the CV\% value, except for the LLOQ where it should not exceed $20 \%$ of the CV\% value.
Table 6: Intra-day accuracy and precision PZA, RIF, INH, AcINH, and EMB.

\begin{tabular}{|c|c|c|c|c|}
\hline \multicolumn{5}{|c|}{ PZA } \\
\hline & LLOQ & LQC & MQC & HQC \\
\hline Accu. $(\%)$ & $102.5 \pm 10.1$ & $93.2 \pm 1.8$ & $90.5 \pm 3.8$ & $91.8 \pm 1.8$ \\
\hline CV (\%) & 9.9 & 1.9 & 4.2 & 2.0 \\
\hline \multicolumn{5}{|c|}{ RIF } \\
\hline & LLOQ & LQC & MQC & HQC \\
\hline Accu.(\%) & $118.1 \pm 11.8$ & $101.6 \pm 3.7$ & $98.4 \pm 2.9$ & $100.4 \pm 3.0$ \\
\hline CV (\%) & 10.0 & 3.6 & 3.0 & 3.0 \\
\hline \multicolumn{5}{|c|}{ INH } \\
\hline & LLOQ & LQC & MQC & HQC \\
\hline Accu.(\%) & $97.2 \pm 13.1$ & $104.0 \pm 5.7$ & $101.7 \pm 5.0$ & $98.4 \pm 3.0$ \\
\hline CV (\%) & 13.4 & 5.5 & 4.9 & 3.0 \\
\hline \multicolumn{5}{|c|}{ AcINH } \\
\hline & LLOQ & LQC & MQC & HQC \\
\hline Accu.(\%) & $90.9 \pm 10.0$ & $97.3 \pm 13.0$ & $98.5 \pm 4.3$ & $98.2 \pm 3.2$ \\
\hline CV (\%) & 11.0 & 13.4 & 4.4 & 3.2 \\
\hline \multicolumn{5}{|c|}{ EMB } \\
\hline & LLOQ & LQC & MQC & HQC \\
\hline Accu. $(\%)$ & $100.6 \pm 18.9$ & $88.9 \pm 4.4$ & $90.1 \pm 3.2$ & $89.6 \pm 1.5$ \\
\hline CV (\%) & 18.8 & 4.9 & 3.5 & 1.7 \\
\hline
\end{tabular}


Compound name: Pyrazinamide

Correlation coefficient $r=0.996985, r^{\wedge} 2=0.993980$

Calibration curve: $0.0556342{ }^{*} x+0.0046854$

Response type: Internal Std (Ref 6 ), Area * (IS Conc. / IS Area)

Curve type: Linear, Origin: Exclude, Weighting: 1/x^2, Axis trans: None

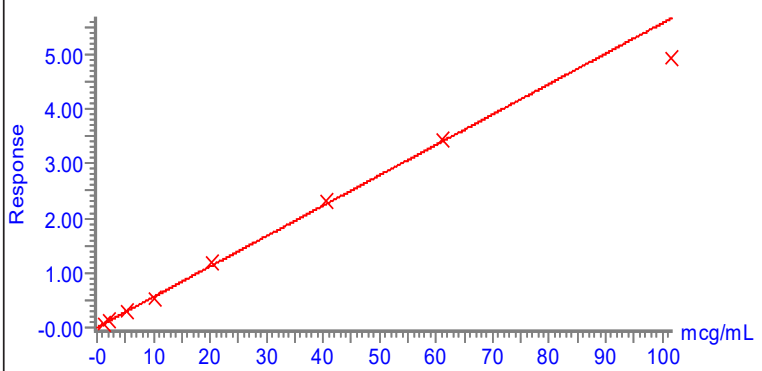

Compound name: Isoniazid

Correlation coefficient: $r=0.994461, r^{\wedge} 2=0.988953$

Calibration curve: $0.106207{ }^{*} x+0.00234345$

Response type: Internal Std (Ref6), Area * (IS Conc. / IS Area )

Curve type: Linear, Origin: Exclude, Weighting: $1 / x^{\wedge} 2$, Axis trans: None

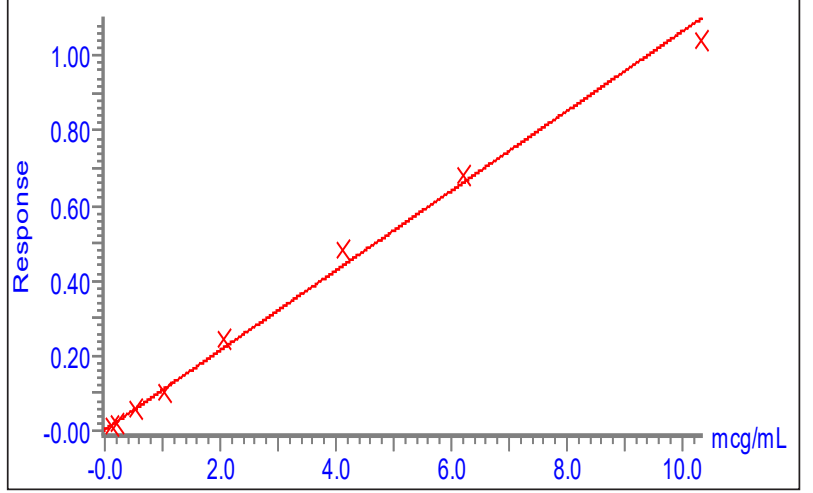

Compound name: Rifampicin

Correlation coefficient: $r=0.995488, r^{\wedge} 2=0.990997$

Calibration curve: $0.0573233{ }^{*} x+-0.00328415$

Response type: Internal Std ( Ref 6 ), Area * (IS Conc. / IS Area )

Curve type: Linear, Origin: Exclude, Weighting: $1 / x^{\wedge} 2$, Axis trans: None

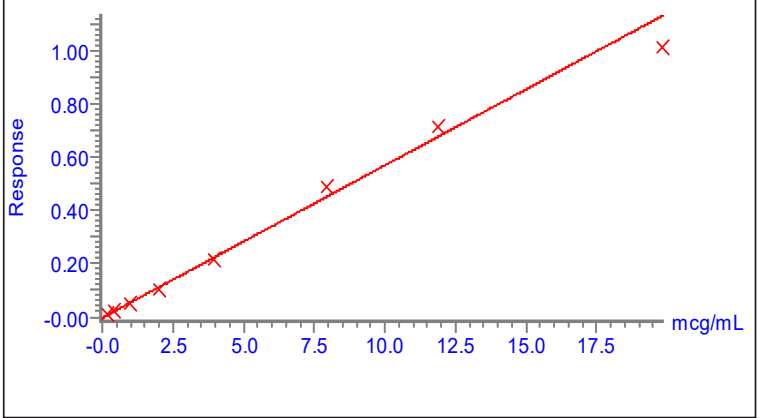

Compound name: Acetylisoniazid

Correlation coefficient: $r=0.997975, r^{\wedge} 2=0.995954$

Calibration curve: $0.0599539 * x+-3.19964 \mathrm{e}-005$

Response type: Internal Std ( Ref6), Area * (IS Conc. / IS Area)

Curve type: Linear, Origin: Exclude, Weighting: 1/x^2, Axis trans: None

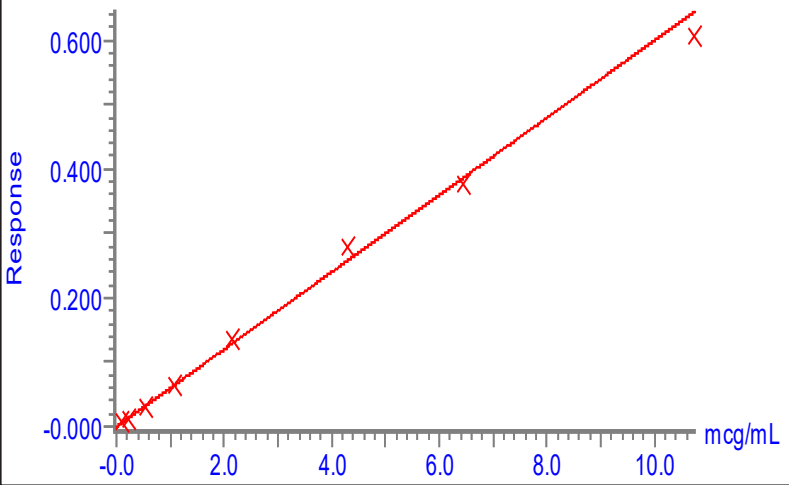

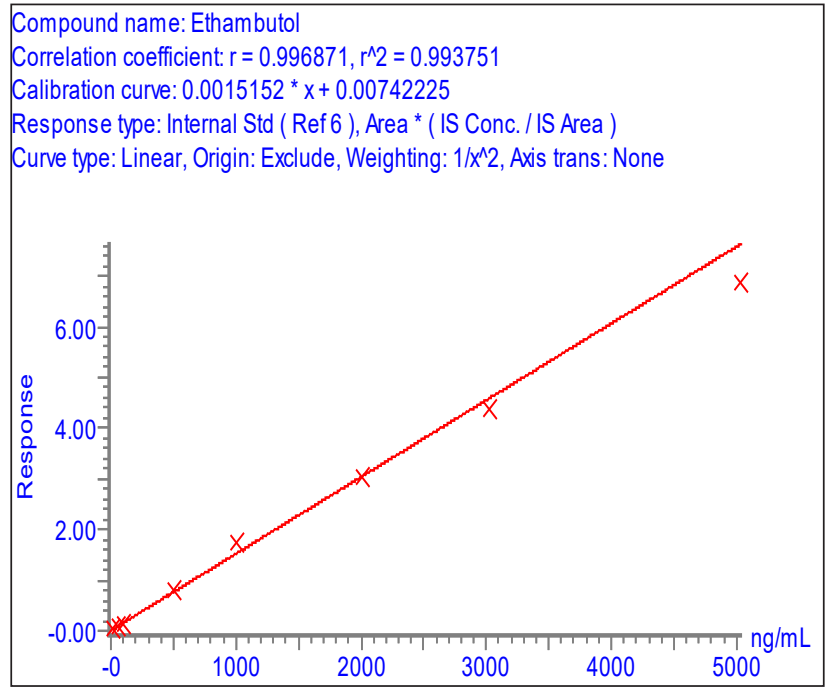

Fig. 5: Calibration curves with the weighting factor of $1 / \mathrm{x}^{2}-\mathrm{PZA}, \mathrm{RIF}, \mathrm{INH}, \mathrm{ACIH}$ and EMB. 
Table 7: Inter-day precision PZA, RIF, INH, AcINH and EMB $(n=5)$.

\begin{tabular}{|c|c|c|c|c|}
\hline & \multicolumn{4}{|c|}{ PZA } \\
\hline & LLOQ & LQC & MQC & HQC \\
\hline Accu. $(\%)$ & $102.1 \pm 9.2$ & $101.4 \pm 8.3$ & $100.6 \pm 7.2$ & $100.3 \pm 6.5$ \\
\hline \multirow[t]{3}{*}{ CV (\%) } & 9.0 & 8.1 & 7.2 & 6.4 \\
\hline & \multicolumn{4}{|c|}{ RIF } \\
\hline & LLOQ & LQC & MQC & HQC \\
\hline Accu. (\%) & $101.1 \pm 14.3$ & $94.2 \pm 8.1$ & $95.9 \pm 4.9$ & $99.0 \pm 6.2$ \\
\hline \multirow[t]{3}{*}{ CV (\%) } & 14.2 & 8.6 & 5.1 & 6.2 \\
\hline & \multicolumn{4}{|c|}{ INH } \\
\hline & LLOQ & LQC & MQC & HQC \\
\hline Accu. (\%) & $98.5 \pm 14.0$ & $100.0 \pm 9.6$ & $100.1 \pm 8.0$ & $99.0 \pm 7.0$ \\
\hline \multirow[t]{3}{*}{ CV (\%) } & 14.2 & 9.6 & 8.0 & 7.1 \\
\hline & \multicolumn{4}{|c|}{ AcINH } \\
\hline & LLOQ & LQC & MQC & HQC \\
\hline Accu. (\%) & $101.5 \pm 14.6$ & $105.0 \pm 12.0$ & $104.2 \pm 7.1$ & $104.0 \pm 5.8$ \\
\hline \multirow[t]{3}{*}{ CV (\%) } & 14.4 & 11.4 & 6.8 & 5.5 \\
\hline & \multicolumn{4}{|c|}{ EMB } \\
\hline & LLOQ & LQC & MQC & $\mathrm{HQC}$ \\
\hline Accu. (\%) & $103.0 \pm 18.1$ & $97.7 \pm 10.1$ & $96.3 \pm 7.1$ & $92.8 \pm 4.7$ \\
\hline CV (\%) & 17.6 & 10.3 & 7.3 & 5.0 \\
\hline
\end{tabular}

Our method has LLOQ (PZA: $1.0 \mu \mathrm{g} / \mathrm{mL}$; RIF: $0.2 \mu \mathrm{g}$ / mL; INH: $0.1 \mu \mathrm{g} / \mathrm{mL}$; AcINH: $0.1 \mu \mathrm{g} / \mathrm{mL}$ and EMB: $20 \mathrm{ng} / \mathrm{mL}$ ) lower than other methods, and linear range was larger (PZA 1.0 $100 \mu \mathrm{g} / \mathrm{mL}$; RIF $0.2-20 \mu \mathrm{g} / \mathrm{mL}$, INH $0.1-10 \mu \mathrm{g} / \mathrm{mL}$, and EMB 20-5000 ng/mL) as compared with previous methods: Prahl's method: PZA: 4-80 $\mu \mathrm{g} / \mathrm{mL}$, RIF: $0.75-30 \mu \mathrm{g} / \mathrm{mL}$, INH: $0.5-10$ $\mu \mathrm{g} / \mathrm{mL}$, EMB: 0.25-10 $\mu \mathrm{g} / \mathrm{mL}$ (Prahl et al., 2016); Sang Hoon Song's method: PZA: 0.4-291.2 $\mu \mathrm{g} / \mathrm{mL}, \mathrm{RIF}: 1.1-320 \mu \mathrm{g} / \mathrm{mL}$, INH: $1.1-320 \mu \mathrm{g} / \mathrm{mL}$, and EMB: $0.07-17.5 \mu \mathrm{g} / \mathrm{mL}$ (Song et al., 2007 ) and Sturkenboom's method: INH: 0.2-8 mg/L; EMB: 0.2-8 mg/L; PZA: 2-80 mg/L (Sturkenboom et al., 2015). Furthermore, the total analysis time in our method was short, about 8 minutes, can detect and quantify exactly the concentration of 5 active analytes and the internal standard.

\section{Recovery}

The method was found to have the good recovery. The results were shown in Table 8.

\section{Extraction method}

Due to the physical and chemical properties of PZA, RIF, $\mathrm{INH}, \mathrm{EMB}$, and AcINH (water-soluble compounds), most authors used extraction method as protein precipitation. In our method, we have developed a simple, easy-to-implement, economic, environmental and human-friendly method. We used only one step of protein precipitation with $100 \% \mathrm{MeOH}$, while other authors have used the method more complex, more time-consuming and more extraction steps. Prahl et al., have used two steps in their method. The first step they precipitated protein with $50 \% \mathrm{MeOH}$ and stored at $-20^{\circ} \mathrm{C}$ for $1 \mathrm{~h}$. The second step was followed by centrifugation to eliminate precipitation, and then continued precipitated with acetonitrile. (Prahl et al., 2016). Sang Hoon Song also extracted sample by two steps: the first step with $50 \% \mathrm{MeOH}$ and second step used $\mathrm{MeOH}$ (Song et al., 2007). Our method also showed that recovery rates of the studied compounds were relatively high (over $60 \%$ and nearly $95 \%$ ) and stable (recovered rates at different levels of LQC, MQC, and HQC were not more than 15\%) (Table 8).

Table 8: Recovery of IS, PZA, RIF, INH, AcINH, EMB.

\begin{tabular}{|c|c|c|c|}
\hline \multicolumn{4}{|l|}{ Recovery (\%) } \\
\hline \multicolumn{4}{|c|}{ PZA } \\
\hline & LQC & MQC & HQC \\
\hline Recovery (\%) & 94.5 & 88.5 & 83.7 \\
\hline & LQC & MQC & HQC \\
\hline Recovery $(\%)$ & 65.6 & 65.1 & 63.5 \\
\hline \multicolumn{4}{|c|}{ INH } \\
\hline Recovery (\%) & 63.7 & 64.6 & 59.4 \\
\hline \multicolumn{4}{|c|}{ AcINH } \\
\hline & LQC & MQC & HQC \\
\hline Recovery (\%) & 79.5 & 76.1 & 69.2 \\
\hline \multicolumn{4}{|c|}{ EMB } \\
\hline
\end{tabular}

\section{Dilution integrity}

Concentrations of anti-TB drugs in human plasma have been reported vary in a wide range. Some samples may have a concentration higher than the ULOQ of the calibration curves. To validate the dilution integrity of the method, the accuracy and precision were assayed using three QC samples spiked with each drug at concentrations higher than the ULOQ with additional series of dilutions. Our data showed that the mean accuracy was in the range of $85-115 \%$ of the nominal concentration and the precision was not exceeded $15 \%$ of the CV for all five drugs (Table 9). The results suggest that if samples have drug concentrations higher than upper of the calibration curve, sample dilution could be performed for reanalysis. 
Table 9: Results of dilution integrity for PZA, RIF, INH, AcINH, and EMB.

\begin{tabular}{|c|c|c|c|}
\hline \multicolumn{4}{|c|}{ PZA } \\
\hline & LDC & MDC & HDC \\
\hline Accu. (\%) & $106.4 \pm 6.1$ & $107.6 \pm 3.7$ & $98.2 \pm 2.8$ \\
\hline CV (\%) & 5.7 & 3.4 & 2.9 \\
\hline \multicolumn{4}{|c|}{ RIF } \\
\hline & LDC & MDC & HDC \\
\hline Accu.(\%) & $103.8 \pm 6.8$ & $105.3 \pm 4.6$ & $100.3 \pm 5.1$ \\
\hline CV (\%) & 6.5 & 4.4 & 5.1 \\
\hline \multicolumn{4}{|c|}{ INH } \\
\hline & LDC & MDC & HDC \\
\hline Accu.(\%) & $107.5 \pm 8.8$ & $112.7 \pm 3.8$ & $104.2 \pm 5.7$ \\
\hline CV (\%) & 8.2 & 3.4 & 5.5 \\
\hline \multicolumn{4}{|c|}{ AcINH } \\
\hline & LDC & MDC & HDC \\
\hline Accu.(\%) & $102.0 \pm 10.7$ & $107.1 \pm 2.9$ & $98.1 \pm 3.8$ \\
\hline $\mathrm{CV}(\%)$ & 10.5 & 2.7 & 3.9 \\
\hline \multicolumn{4}{|c|}{ EMB } \\
\hline & LDC & MDC & HDC \\
\hline Accu.(\%) & $112.6 \pm 4.5$ & $105.1 \pm 2.6$ & $98.8 \pm 3.1$ \\
\hline CV (\%) & 4.0 & 2.5 & 3.1 \\
\hline
\end{tabular}

\section{Stability}

\section{Autosampler stability}

The autosampler stability test showed no significant bias between fresh and stored samples based on the difference between the concentration of the stored processed samples and that of the freshly processed samples should not exceed $15 \%$, and $\mathrm{CV} \%$ of determinations of samples at each concentration should not exceed $15 \%$. The results are presented in Table 10 .

\section{Short-term stability}

The criterion for short-term stability is the difference between the concentration of the stored plasma samples with that of freshly prepared samples should not exceed $15 \%$. CV\% of determinations of samples at each concentration should not exceed $15 \%$. The results were presented in Table 11. Short-term stability test showed that INH and AcINH in human plasma were stabled after 2 hours but was unstable after 4 hours stored at room temperature.

\section{Long-term stability}

The requirement for long-term stability is the difference between the concentration of the stored samples and that of freshly prepared samples should not exceed $15 \%$ and the CV\% of determinations of samples at each concentration should not exceed $15 \%$. The results were presented in Table 12 . Long-term stability test showed that all samples in human plasma were stabled after 18 days stored at $-70^{\circ} \mathrm{C} \pm 5^{\circ} \mathrm{C}$.

Concentration monitoring of PZA, RIF, AcINH, INH, and EMB has been attracted many researchers. Julie et al., also have developed a method for simultaneous quantification of pyrazinamide, rifampicin, isoniazid, and ethambutol by liquid chromatography/tandem mass spectrometry. In that study, they used isotopically labeled compounds as internal standards. As compared with our method, ours has wide linear range of the calibration curve than theirs, such as in their method, for PZA $4-80 \mu \mathrm{g} / \mathrm{mL}$, for RIF $0.75-30 \mu \mathrm{g} /$ $\mathrm{mL}$, for INH was $0.5-10 \mu \mathrm{g} / \mathrm{mL}$, for EMB $0.25-10 \mu \mathrm{g} / \mathrm{mL}$ and meanwhile in our method was for PZA $1.0-100 \mu \mathrm{g} / \mathrm{mL}$; RIF $0.2-20 \mu \mathrm{g} / \mathrm{mL}$, INH $0.1-10 \mu \mathrm{g} / \mathrm{mL}$, and EMB 20-5000 ng/mL (Prahl et al., 2016). Sang Hoon Song et al., also have developed a method to measure concentrations of four antituberculosis drugs (isoniazid, rifampicin, pyrazinamide, and ethambutol) and two major metabolic ratios (acetylisoniazid/ isoniazid and 25-desacetylrifampicin/rifampicin). Their method showed the linearity range for PZA, RIF, INH, and EMB was 0.4-291.2, 1.1-320, 0.07-18.6, and 0.07-17.5 $\mu \mathrm{g} / \mathrm{mL}$, respectively (Song et al., 2007). Marieke et al. also developed a method to quantify isoniazid, pyrazinamide, and ethambutol in serum using isotope-labeled isoniazid-D4 and ethambutol-D4 as internal standards. In that method, the range of quantification for isoniazid and ethambutol was $0.2-8 \mathrm{mg} / \mathrm{L}$; and for pyrazinamide 2-80 mg/L (Sturkenboom et al., 2015). Compared with previous methods, our method was effective to determine plasma concentrations of PZA, RIF, INH, AcINH, and EMB, and can be used to monitor drug concentrations in TB treatment. 
Table 10: Results of autosampler stability: PZA, RIF, INH, AcINH, and EMB.

\begin{tabular}{|c|c|c|c|c|}
\hline \multicolumn{5}{|c|}{ PZA } \\
\hline & LQC Freshly processed & LQC After 20 hours $/ 10^{\circ} \mathrm{C}$ & HQC Freshly processed & HQC After 20 hours $/ 10^{\circ} \mathrm{C}$ \\
\hline CV (\%) & 3.8 & 4.8 & 3.3 & 5.0 \\
\hline Variation (\%) & \multicolumn{2}{|c|}{-0.7} & \multicolumn{2}{|c|}{-6.6} \\
\hline \multicolumn{5}{|c|}{ RIF } \\
\hline CV (\%) & 4.0 & 5.0 & 3.1 & 5.2 \\
\hline Variation (\%) & \multicolumn{2}{|c|}{14.6} & \multicolumn{2}{|c|}{0.5} \\
\hline \multicolumn{5}{|c|}{ INH } \\
\hline CV (\%) & 6.5 & 12.0 & 5.1 & 5.1 \\
\hline Variation (\%) & \multicolumn{2}{|c|}{-12.7} & \multicolumn{2}{|c|}{-11.7} \\
\hline \multicolumn{5}{|c|}{ AcINH } \\
\hline CV (\%) & 8.4 & 8.4 & 2.9 & 4.2 \\
\hline Variation (\%) & \multicolumn{2}{|c|}{9.0} & \multicolumn{2}{|c|}{2.6} \\
\hline \multicolumn{5}{|c|}{ ЕМB } \\
\hline CV (\%) & 5.5 & 7.1 & 2.4 & 5.5 \\
\hline Variation (\%) & \multicolumn{2}{|c|}{-3.5} & \multicolumn{2}{|c|}{-6.4} \\
\hline
\end{tabular}

Table 11: Results of short-term stability of plasma samples: PZA, RIF, INH, ACINH, and EMB.

\begin{tabular}{|c|c|c|c|c|c|c|}
\hline & LQC Freshly processed & HQC Freshly processed & $\begin{array}{l}\text { LQC After } 2 \text { hours/ } \\
\text { room temperature }\end{array}$ & $\begin{array}{l}\text { HQC After } 2 \text { hours/ } \\
\text { room temperature }\end{array}$ & $\begin{array}{l}\text { LQC After } 4 \text { hours/ } \\
\text { room temperature }\end{array}$ & $\begin{array}{l}\text { HQC After } 4 \text { hours/ } \\
\text { room temperature }\end{array}$ \\
\hline \multicolumn{7}{|c|}{ PZA } \\
\hline \multirow[t]{2}{*}{ CV (\%) } & 3.7 & 3.5 & 10.0 & 4.3 & 5.8 & 2.7 \\
\hline & Variation (\%) & & 13.0 & 5.6 & 13.6 & 0.5 \\
\hline \multicolumn{7}{|c|}{ RIF } \\
\hline \multirow[t]{2}{*}{ CV (\%) } & 4.6 & 4.8 & 7.8 & 4.8 & 7.8 & 4.9 \\
\hline & Variation (\%) & & 13.4 & 1.6 & 14.8 & -7.3 \\
\hline \multicolumn{7}{|c|}{ INH } \\
\hline \multirow[t]{2}{*}{ CV (\%) } & 9.4 & 1.1 & 12.0 & 3.7 & 7.0 & 1.8 \\
\hline & Variation (\%) & & 5.1 & -8.2 & -11.2 & $-18.4^{*}$ \\
\hline \multicolumn{7}{|c|}{ AcINH } \\
\hline \multirow[t]{2}{*}{ CV (\%) } & 8.0 & 1.6 & 10.2 & 5.0 & 7.6 & 3.8 \\
\hline & Variation (\%) & & 10.4 & -14.9 & -7.8 & $-24.1^{*}$ \\
\hline \multicolumn{7}{|c|}{ EMB } \\
\hline \multirow[t]{2}{*}{ CV (\%) } & 6.0 & 3.5 & 5.7 & 5.5 & 6.7 & 3.8 \\
\hline & Variation (\%) & & 14.0 & 4.8 & 14.1 & -2.4 \\
\hline
\end{tabular}

*: unstable 
Table 12: Results of long-term stability of plasma samples: PZA, RIF, INH, ACINH, and EMB.

\begin{tabular}{|c|c|c|c|c|c|c|}
\hline Conc. $(\mu \mathrm{g} / \mathrm{mL})$ & LQC Freshly processed & HQC Freshly processed & LQC After 5 days & HQC After 5 days & LQC After 18 days & HQC After 18 days \\
\hline \multicolumn{7}{|c|}{ PZA } \\
\hline \multirow[t]{2}{*}{ CV (\%) } & 8.5 & 7.7 & 6.2 & 4.2 & 5.0 & 4.4 \\
\hline & Variation (\%) & & -7.3 & -9.6 & 4.6 & 7.9 \\
\hline \multicolumn{7}{|c|}{ RIF } \\
\hline \multirow[t]{2}{*}{ CV (\%) } & 6.5 & 8.7 & 8.5 & 4.9 & 6.4 & 5.3 \\
\hline & Variation (\%) & & -6.7 & -9.4 & -4.5 & -9.3 \\
\hline \multicolumn{7}{|c|}{ INH } \\
\hline \multirow[t]{2}{*}{ CV (\%) } & 5.9 & 6.1 & 3.9 & 3.0 & 4.6 & 4.3 \\
\hline & Variation (\%) & & -8.6 & -3.4 & -5.7 & -6.0 \\
\hline \multicolumn{7}{|c|}{ AcINH } \\
\hline \multirow[t]{2}{*}{ CV (\%) } & 9.7 & 7.6 & 6.2 & 3.6 & 3.6 & 3.5 \\
\hline & Variation (\%) & & -8.7 & -0.5 & -5.0 & -3.0 \\
\hline \multicolumn{7}{|c|}{ ЕМB } \\
\hline \multirow[t]{2}{*}{ CV (\%) } & 6.6 & 4.9 & 2.6 & 3.0 & 6.2 & 3.9 \\
\hline & Variation (\%) & & -14.3 & -9.9 & -14.5 & -6.5 \\
\hline
\end{tabular}

\section{CONCLUSIONS}

We have shown a rapid, simple, selective, and sensitive LC-MS/MS method for the simultaneous analysis of PZA, RIF, INH, AcINH, and EMB in human plasma. The results of validation for specificity/selectivity, precision, accuracy, linearity, limit of quantification, recovery, and stability showed that the method meets the requirements of a bioanalytical method. Our method may serve well for routine therapeutic monitoring of the first-line anti-TB drugs in patient plasma.

\section{ABBREVIATION}

AcINH: Acetyl Isoniazid;

EMB: Ethambutol;

INH: Isoniazid;

PZA: Pyrazinamide;

RIF: Rifampicin;

DIL: Diltiazem hydrochloride;

MF: matrix factor;

LQC: low-quality control;

MQC: medium quality control;

HQC: high-quality control.

\section{CONFLICTS OF INTEREST}

The authors declare that there are no conflicts of interest.

\section{ACKNOWLEDGMENTS}

This study was supported by a grant from the Vietnam Ministry of Science and Technology, and Newton Fund Vietnam (Grant Number HNQT/SPĐP/01.06).

\section{REFERENCES}

Agency EM. Guideline on bioanalytical method validation.
Committee for Medicinal Products for Human Use (CHMP). 2011.

Alsultan A, Peloquin CA. Therapeutic drug monitoring in the treatment of tuberculosis: an update. Drugs, 2014; 74(8):839-854.

Health UDo, Services H, Food, Administration D (2017). Analytical procedures and methods validation for drugs and biologicsguidance for industry. 2015.

Hoa NB, Sy DN, Nhung NV, Tiemersma EW, Borgdorff MW, Cobelens FG. National survey of tuberculosis prevalence in Viet Nam. Bulletin of the World Health Organization, 2010; 88(4):273-280.

Mirsaeidi M, Sadikot RT. Patients at high risk of tuberculosis recurrence. International journal of mycobacteriology, 2018; 7(1):1.

Molden E, Bøe GH, Christensen H, Reubsaet L. Highperformance liquid chromatography-mass spectrometry analysis of diltiazem and 11 of its phase I metabolites in human plasma. Journal of pharmaceutical and biomedical analysis, 2003; 33(2):275-285.

Mukherjee A, Velpandian T, Singla M, Kanhiya K, Kabra SK, Lodha R. Pharmacokinetics of isoniazid, rifampicin, pyrazinamide and ethambutol in Indian children. BMC infectious diseases, 2015; 15(1):126.

Mukherjee JS, Rich ML, Socci AR, Joseph JK, Virú FA, Shin SS, Furin JJ, Becerra MC, Barry DJ, Kim JY. Programmes and principles in treatment of multidrug-resistant tuberculosis. The Lancet, 2004; 363(9407):474-481.

Prahl JB, Lundqvist M, Bahl J, Johansen IS, Andersen ÅB, Frimodt-Møller N, Cohen AS. Simultaneous quantification of isoniazid, rifampicin, ethambutol and pyrazinamide by liquid chromatography/ tandem mass spectrometry. Apmis, 2016; 124(11):1004-1015.

Song SH, Jun SH, Park KU, Yoon Y, Lee JH, Kim JQ, Song J. Simultaneous determination of first-line anti-tuberculosis drugs and their major metabolic ratios by liquid chromatography/tandem mass spectrometry. Rapid communications in mass spectrometry, 2007; 21(7):1331-1338.

Sturkenboom M, van der Lijke H, Jongedijk E, Kok WT, Greijdanus B, Uges D, Alffenaar J-WC. Quantification of isoniazid, pyrazinamide and ethambutol in serum using liquid chromatographytandem mass spectrometry. Journal of Applied Bionalysis, 2015; $1(3): 89$.

Um S, Lee S, Kwon S, Yoon H, Park K, Song J, Lee C, Lee J. Low serum concentrations of anti-tuberculosis drugs and determinants 
of their serum levels. The International Journal of Tuberculosis and Lung Disease, 2007; 11(9): 972-978.

Zhou Z, Wu X, Wei Q, Liu Y, Liu P, Ma A, Zou F. Development and validation of a hydrophilic interaction liquid chromatography-tandem mass spectrometry method for the simultaneous determination of five first-line antituberculosis drugs in plasma. Analytical and bioanalytical chemistry, 2013; 405(19):6323-6335.
How to cite this article:

Luyen LT, Hung TM, Huyen LT, Tuan LA, Huong DTL, Duc HV, Tung BT. Simultaneous determination of Pyrazinamide, Rifampicin, Ethambutol, Isoniazid and Acetyl Isoniazid in human plasma by LC-MS/MS method. J App Pharm Sci, 2018; 8(09): 061-073. 